\title{
Idiopathic Hypereosinophilic Syndrome Presenting as IgA Nephropathy with Nephrotic Range Proteinuria
}

\author{
Tajamul H. Shah, Ajaz N. Koul, Sonaullah Shah, Umar H. Khan, Parvaiz A. Koul, Fayaz A. Sofi, \\ Mufti S., Rafi Ahmed Jan* \\ Intrenal \& Pulmonary Medicine, Sheri Kashmir Institute of Medicine, Srinagar, India \\ Email: rafiahmedjan@gmail.com
}

Received March 7, 2013; revised May 1, 2013; accepted May 16, 2013

Copyright (C) 2013 Rafi Ahmed Jan et al. This is an open access article distributed under the Creative Commons Attribution License, which permits unrestricted use, distribution, and reproduction in any medium, provided the original work is properly cited.

\begin{abstract}
Idiopathic hypereosinophilic syndrome (IHES) is a disorder characterized by increased eosinophil count (eosinophilia) along with organ dysfunction secondary to organ infiltration of eosinophils and release of inflammatory markers [1-4], with no obvious cause for eosinophilia. The onset of symptoms is insidious in most of the cases and eosinophilia is detected incidentally. However, in others, the initial manifestations are severe and life-threatening due to the rapid evolution of cardiac or neurologic complications [5]. Renal involvement is rarely reported [6] in IHES. Herein we reported a case of IHES with predominant renal involvement as nephrotic syndrome with focal necrotizing IgA nephropathy.
\end{abstract}

Keywords: Idiopathic Hypereosinophilic Syndrome; Eosinophilia; Renal Involvement; Nephrotic Syndrome

\section{Case Report}

A 50-year old male presented with a 3-week history of a non-productive cough, associated with intermittent low grade fever, periorbital puffiness and lower extremity edema. Patient denied any history of breathlessness, chest-pain, hemoptysis, orthopnea, paroxysmal nocturnal dyspnea, drop in urine output, skin rash or arthritis. His past history was insignificant and he denied any history of drug intake.

Hisexamination revealed mild pallor, with periorbitalpuffiness, lower extremity pitting edema and mild splenomegaly. He had hemoglobin of $11 \mathrm{~g} / \mathrm{dL}$ with a total leucocyte count of $9.2 \times 10 \%$ cumm and an ESR of $23 \mathrm{mmhr}$. His differential count included $46 \%$ polymorphs $11 \%$ lymphocytes and $41 \%$ eosinophils with AEC count of 3800 which repeatedly was high and ranged from 3800 to 5500. A peripheral blood film showed features of normochromic normocytic anaemia with no abnormal cells. His serum creatinine was 1.7 $\mathrm{mg} / \mathrm{dL}$ with a creatinine clearance of $44 \mathrm{ml} / \mathrm{min}$. Liver functions showed hypoporoteinemia with hypoalbuminemia. He had an active urinary sedimentand urine which showed presence of eosinophils on wright's stain-

\footnotetext{
"Corresponding author.
}

ing. 24 hours urinary protein was $5.04 \mathrm{~g} / 24$ hours which was reproduced twice. Repeated stool examination for the presence of ova/parasite was negative.

Radiograph of the chest was normal. High resolution computerized tomography of the chest did not reveal any abnormality. His electrocardiograph and echocardiography were normal. Ultrasonography of abdomen was normal as well.

Patient was investigated further to look for eosinophilic infiltration of other organ systems in view of persistant hypereosinophilia.

Patient was subjected to bronchoscopy to obtain bronchoalveolar lavage for eosinophils which revealed $62 \%$ eosinophils. Bone marrow aspiration and biopsy revealed 56\% eosinophils with no dysplasia and blasts. p-ANCA andc-ANCA were within normal limits. Serum tryptase levels were within normal limits.

Patient was subjected to percutaneous renal biopsy to look for the etiology of nephrotic range proteinuria. Renal biopsy revealed, marked interstitial edema and patchy inflammation including aggregates of eosinophils admixed with mononuclear cells and occasional neutrophils. An eosinophilic infiltrate was also seen in medulla with eosinophillic tubulitis and patchy destruction of tubular basement membrane. Direct immunofluorescence showed 
deposition of IgA, IgG, IgM and $\mathrm{C}_{3}$ predominantly in mesangium with final impression of foal necrotizing IgA nephropathy (Figure 1).

A diagnosis of Idiopathic hypereosinophilia with renal involvement in the form of focal necrotizing IgA nephropathy presenting as nephrotic syndrome was made.

Patient was started on $1 \mathrm{mg} / \mathrm{kg} /$ day of prednisolone. Repeat eosinophil count after 2 weeks of steroids was within normal limits and protein was undetectable in urine after 4 weeks of steroid therapy.

\section{Discussion}

IHES is a group of disorders characterized by sustained overproduction of eosinophil's in which eosinophillic infiltration and mediator release cause damage to organ. Renal involvement in IHES is reported rarely [6,7], limited mostly to the case reports. Renal involvement could be the first manifestation of HES [8]. The first case of renal involvement in IHES was reported in 1979 by Lanfranchi et al. [9]. They observed glomerular sclerosis and eosinophilicintersititial infiltrate on renal histology.

Renal involvement can present as renal dysfunction [5,6] or proteinuria [10], which can range from subnephrotic to nephrotic range [11]. Our case presented with renal dysfunction with serum creatinine of 1.7 and creatinine clearance of $44 \mathrm{ml} / \mathrm{min}$. He also had nephrotic range proteinuria which was reproduced twice.

There is not much literature on renal histological pattern in IHES [12]. Various histological patterns reported by various authors include Ischemic lesions secondary to intrarenal thrombus formation [13], crescentic glomerulonephritis [14], mesangial expansion [15], proliferative glomerulonephritis [13], immuno-tactoid glomerulopath [11], glomerular sclerosis [6], interstitial nephritis with

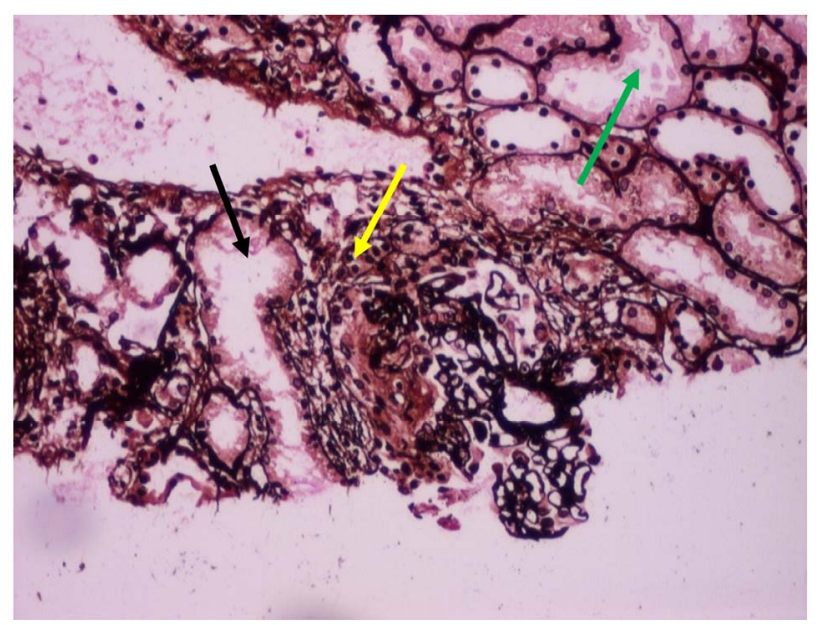

Figure 1. Microscopic view of kidney biopsy (H \& E) Eosinophilic infiltration (yellow arrow), tubular epithelial shedding (black arrow) and tubular casts (green arrow). eosinophilic infil-trates $[8,10]$ and membranous nephropathy [11]. Findings on immunofluorescence of renal biopsy in patients with IHES vary with deposition of immune complex and complement in some cases and lack of their deposition in others.

In our case the histological features were suggestive of eosinophilic interstitial infiltrate and focal necrotizing IgA nephropathy. There was deposition of immunoglobulin'sand compliment.

This is probably the first case reported in literature till date of renal involvement in patient with IHES.

Renal involvement with peripheral eosinophilia can occur in a number of conditions like drugs [16], myeloproliferative disorders [17], parasitic manifestation [18], cholesterol embolization [19] or necrotizing vasculitis. No such cause was obvious from history and investigations in our case.

Treatment is indicated in all symptomatic patients or those with evidence of organ dysfunction.

Steroids are the initial therapy of choice [20] for patients with organ involvement who do NOT have the FIP1L1-PDGFRA fusion or another imatinib-sensitive tyrosine kinase mutation. In the large series, partial or complete remission was achieved in 85 percent at one month (4 weeks).

Other drugs include hydoxyurea, or Anti-IL-5 [20-22], either adding to steroids or as steroid sparing.

We managed our patient with oral prednisolone 60 $\mathrm{mg} /$ day (1 $\mathrm{mg} / \mathrm{kg} /$ day). Patient was reevaluated at 2 weeks of steroid therapy for eosinophil count and proteinuria. At 2 weeks AEC was within normal limits but proteinuria persisted although decreased. At 4 weeks AEC was within normal limits and proteinuria had settled.

\section{REFERENCES}

[1] P. F. Weller and G. J. Bubley, "The Idiopathic Hypereosinophilic Syndrome,” Blood, Vol. 83, No. 10, 1994, p. 2759.

[2] F. Roufosse, E. Cogan and M. Goldman, "Recent Advances in Pathogenesis and Management of Hypereosinophilic Syndromes,” Allergy, Vol. 59, No. 7, 2004, pp. 673-689. doi:10.1111/j.1398-9995.2004.00465.X

[3] A. D. Klion, B. S. Bochner, G. J. Gleich, et al., “Approaches to the Treatment of Hypereosinophilic Syndromes: A Workshop Summary Report,” Journal of Allergy and Clinical Immunology, Vol. 117, No. 6, 2006, pp. 1292-1302. doi:10.1016/j.jaci.2006.02.042

[4] J. Sheikh and P. F. Weller, "Clinical Overview of Hypereosinophilic Syndromes,” Immunology and Allergy Clinics of North America, Vol. 27, No. 3, 2007, pp. 333355. doi:10.1016/j.iac.2007.07.007

[5] V. Ambarus and A. Cosovanu, "The Evolutionary Cha-racteristics of the Hypereosinophilic Syndrome,” Re- 
vista Medico-Chirurgicala a Societatii de Medici si Naturalisti din Lasi'S, Vol. 102, No. 1-2, 1998, pp. 69-75.

[6] J. L. Motellon, C. Bernis, A. Garcia-Sanchez, E. Gruss and J. A. Traver, "Renal Involvement in the HyperEosinophilic Syndrome," Nephrology Dialysis Transplantation, Vol. 10, No. 3, 1995, pp. 401-403.

[7] A. S. Fauci, J. B. Harley, W. C. Roberts, V. J. Ferrans, H. R. Gralmick and B. H. Bhorson, "The Idiopathic Hypereosinophilic Syndrome: Clinical, Pathophy-Siologic and Therapeutic Considerations," Annals of Internal Medicine, Vol. 97, No. 1, 1982, pp. 78-92. doi:10.7326/0003-4819-97-1-78

[8] I. Navarro, J. Torras, M. Gomà, J. M. Cruzado and J. M. Grinyó, "Renal Involvement as the First Manifestation of Hypereosinophilic Syndrome,” Clinical Kidney Journal, Vol. 2, No. 5, 2009, pp. 379-381.

[9] C. J. Spry, J. Davies, P. C. Tai, E. G. Oslen, C. M. Oakley and J. F. Goodwin, "Clinical Features of Fifteen Patients with the Hypereosinophilic Syndrome,” Journal of Nuclear Medicine, Vol. 205, No. 52, 1983, pp. 1-2.

[10] F. Bulucu, C. Can, V. Inal, Y. Baykal and S. Erikci, "Renal Involvement in a Patient with Idiopathic Hypereosinophilic Syndrome,” Clinical Nephrology, Vol. 57, No. 2, 2002, pp. 171-172.

[11] M. Frigui, M. B. Hmida, M. Jallouli, M. Kechaou, F. Frikha and Z. Bahloul, "Membranousglomerulopathy Associated with Idiopathic Hypereosinophilic Syndrome," Saudi Journal of Kidney Diseases and Transplantation, Vol. 21, No. 2, 2010, pp. 320-322.

[12] Y. J. Choi, J. D. Lee, K. H. Yang, B. K. Kim, B. K. Bang and S. I. Shim, "Immunotactoidglomerulopathy Associated with Idiopathic Hypereosinophilic Syndrome,” American Journal of Nephrology, Vol. 18, 1998, pp. 337-343. doi:10.1159/000013362

[13] M. J. Chusid, D. C. Dale, B. C. West and S. M. Wolff, "The Hypereosinophilic Syndrome: Analysis of Fourteen Cases with Review of the Literature,” Medicine, Vol. 54, No. 1, 1975, p. 27.

[14] P. Richardson, G. Dickinson, S. Nash, L. Hoffman, R. Steingard and M. Germain, "Crescentic Glome-Rulone- phritis and Eosinophilic Interstitial Infiltrates in a Patient with Hypereosinophilic Syndrome,” Postgraduate Medical Journal, Vol. 71, 1995, pp. 175-178. doi:10.1136/pgmj.71.833.175

[15] C. P. Guidicelli, F. Didelot, C. Duvic, J. Desrame, M. Herody and G. Nedelec, "Eosinophilia and Renal Pathology,” Medicine Tropicale, Vol. 58, Suppl. 4, 1998, pp. 477- 481.

[16] U. Schnetzke, T. Bossert, et al., "Drug-Induced Lymphadenopathy with Eosinophilia and Renal Failure Mimicking Lymphoma Disease: Dramatic Onset of DRESS Syndrome Associated with Antibiotic Treatment," Annals of Hematology, Vol. 90, No. 11, 2011, pp. 1353-1355.

[17] R Talwar, S. C. Dash, et al., “A Case of Chronic Myeloid Leukemia Complicated with Minimal Change Nephrotic Syndrome,” Acta Haematologica, Vol. 109, No. 2, 2003, pp. 101-103.

[18] M. L. F. van Velthuysen and S. Florquin, "Glomerulopathy Associated with Parasitic Infections," Clinical Microbiological Review, Vol. 13, No. 1, 2000, pp. 55-66.

[19] B. S. Kasinath and E. J. Lewis, "Eosinophilia as a Clue to the Diagnosis of Atheroembolic Renal Disease," Archives of Internal Medicine, Vol. 147, No. 8, 1987, pp. 13841385.

[20] P. U. Ogbogu, B. S. Bochner, J. H. Butterfield, et al., "Hypereosinophilic Syndrome: A Multicenter, Retrospective Analysis of Clinical Characteristics and Response to Therapy,” Journal of Allergy and Clinical Immunology, Vol. 124, No. 6, 2009, pp. 1319-1325. doi:10.1016/j.jaci.2009.09.022

[21] A. B. Kay and A. D. Lion, "Anti-IL-5 Therapy for Asthma and Hypereosinophilicsyndrome," Immunology and Allergy Clinics of North America, Vol. 24, No. 4, 2004, pp. 645-666. doi:10.1016/j.iac.2004.06.007

[22] M. E. Rothenber, et al., "Treatment of Patients with the Hypereosinophilic Syndrome with Mepolizumab,” New England Journal of Medicine, Vol. 358, 2008, pp. 12151228. doi:10.1056/NEJMoa070812 